\title{
The effects of intensive gait training with body weight support treadmill training on gait and balance in stroke disability patients: a randomized controlled trial
}

\author{
Byung Joon Lee ${ }^{a}$, Hwang Jae Lee ${ }^{b}$, Wan Hee Lee ${ }^{c}$ \\ ${ }^{a}$ Department of Rehabilitation Medicine, Inje University Sanggye Paik Hospital, Seoul, Republic of Korea \\ ${ }^{b}$ Department of Physical Therapy, The Graduate School, Sahmyook University, Seoul, Republic of Korea \\ 'Department of Physical Therapy, College of Health and Welfare, Sahmyook University, Seoul, Republic of Korea
}

Objective: The purpose of this study was to investigate the effects of intensive gait training with body weight support treadmill training on gait and balance in stroke disability patients.

Design: Randomized controlled trial.

Methods: Twenty-six stroke patients (20 men and 6 women) participated in this study. All subjects were hospitalized patients. They were randomly divided into two groups: the experimental group (body weight supported treadmill training group, $\mathrm{n}=14$ ) and control group (treadmill group, $\mathrm{n}=12$ ). The mean ages were 52.07 years (experimental group) and 53.83 years (control group). Subjects in both groups received conventional training 10 times/wk. Subjects in the experimental group practiced body weight supported treadmill training for 30 minutes a day, 3 day/wk. Subjects in the control group practiced treadmill training for 30 minutes. The Berg Balance Scale (BBS) and GAITRite were used to evaluate balance and gait parameters (step length, cadence and gait speed) before and after the intervention.

Results: BBS scores in the experimental group showed significantly greater improvement (4.33 \pm 1.54$)$, compared with the control group $(p<0.05)$. Significantly greater improvement in the gait speed $(24.13 \pm 4.53 \mathrm{~cm} / \mathrm{s})$, affected side step length $(10.40 \pm 3.42$ $\mathrm{cm})$, sound side step length $(11.97 \pm 3.29 \mathrm{~cm})$, and cadence $(23.88 \pm 5.52 \mathrm{step} / \mathrm{min})$, compared with the control group $(p<0.05)$.

Conclusions: Intensive gait training with Body Weight Support Treadmill Training may improve gait and balance in subacute stroke.

Key Words: Gait, Postural balance, Stroke, Weight bearing

\section{Introduction}

Stroke is one of the main causes of acquired adult disability in most countries [1]. A patient acquires a disability depending on the position of damage from a stroke. Gait disturbance and balance disorders affect the quality of life and independent activity of daily living. Therefore, there are many attempts to improve gait disturbance and balance disorders of stroke patients [2-6]. Among them, gait training with a treadmill is a task oriented approach that can be trained to operate the walking exercise. It can be adjusted to maintain a constant walking speed of a patient. Therefore, treadmill gait training was used for gait training of stroke patients.

It is the best intervention that should begin as quickly as possible for functional recovery [7,8]. More recently, Body Weight Support Treadmill Training (BWSTT) has been tried for patients who were unable to cope with full weight bearing on their lower limbs. This training consists of using an overhead suspension system and harness to support the body

Received: 23 October, 2013 Revised: 5 December, 2013 Accepted: 17 December, 2013

Corresponding author: Wan Hee Lee

Department of Physical Therapy, College of Health and Welfare, Sahmyook University, 815 Hwarang-ro, Nowon-gu, Seoul 139-742, Republic of Korea Tel: 82-2-3399-1633 Fax: 82-2-3399-1639 E-mail: whlee@syu.ac.kr

(c) This is an Open-Access article distributed under the terms of the Creative Commons Attribution Non-Commercial License (http://creativecommons.org/licens es/by-nc/3.0) which permits unrestricted non-commercial use, distribution, and reproduction in any medium, provided the original work is properly cited.

Copyright @ 2013 Korean Academy of Physical Therapy Rehabilitation Science 
weight of patients [9].

Intensive and graded locomotor activities increased recovery of functional activity [10]. Therefore, intensive gait training is necessary to further improve walking in stroke patients. However, stroke patients cannot be subjected to intensive gait training due to high risk of falls, poor coordination and weakness.

BWSTT provides support to the patient and reduces the loading weight. This study intends to investigate the effects of intensive treadmill training with body weight support on gait and balance for stroke patients who can walk.

\section{Methods}

\section{Subjects}

The subjects were recruited from $M$ Rehabilitation Hospital in Seoul. Twenty-eight subjects (21 men and 7 women) were enrolled in the study. Two subjects from the control group did not complete the study. Table 1 shows the general characteristics of subjects who completed the study.

Inclusion criteria $[11,12]$ were (1) those who were diagnosed stroke shown by computed tomography or magnetic resonance imaging; (2) those who had independent gait ability with or without a walking aid for a minimum of $10 \mathrm{~m}$; (3) no abnormality in the visual and auditory system; and (4) a mini-mental state examination (MMSE-K) score of greater than 24.

Exclusion criteria $[12,13]$ were (1) those who had a history of other neurologic diseases or disorders; (2) abnormality in the cardiovascular system; (3) pain or limited motion of the lower extremity; and (4) could not understand verbal instruction.

This study was approved by the Sahmyook Univerity's institutional review board. All subjects signed a written informed consent prior to participation.

\section{Procedures}

Twenty-eight subjects were randomized into one of the two groups, the experimental group $(n=14)$ and control group ( $\mathrm{n}=14)$. Randomization was computer generated using a basic random number generator. Pre-tests were performed with measurements of balance (Berg Balance Scale [BBS]) and gait (step length, cadence and gait speed). Subjects in both groups participated in a conventional training program twice a day, 5 day/wk for 4 weeks. Subjects in the experimental group practiced BWSTT 30 minutes a day, 3 day/wk for 4 weeks [14,15]. Subjects in the control group practiced treadmill training without body weight support. Frequency was the same as the experimental group. All subjects from the experimental group completed the study. However, two subjects of control group did not complete the study.

\section{Treadmill training program}

Subjects underwent gait training using a treadmill (FITEX T-5050; Fitex, Gwangju, Korea, 2007; Figure 1). Physical therapists observed the training process for patient safety. If patients felt pain or discomfort, dragged their feet, lost their balance, and/or experienced fatigue, a physical therapist immediately stopped the treadmill.

Subjects walked as fast as possible while maintaining a walking pattern close to normal and the initial speed of the

Table 1. General characteristics of the subjects

$(\mathrm{N}=26)$

\begin{tabular}{lcc}
\hline \multicolumn{1}{c}{ Variable } & BWSTT group $(\mathrm{n}=14)$ & Control group $(\mathrm{n}=12)$ \\
\hline Sex, male/female & $11 / 3(78.6 / 21.4)$ & $9 / 3(75 / 25)$ \\
Age (yr) & $52.07(9.64)$ & $53.83(7.40)$ \\
Weight $(\mathrm{kg})$ & $64.45(9.50)$ & $67.10(10.35)$ \\
Height (cm) & $169.26(8.21)$ & $164.48(9.10)$ \\
Month of post stroke & $4(1.18)$ & $6(1.76)$ \\
Side of lesion, right/left & $7 / 7(50 / 50)$ & $4 / 8(33.3 / 66.7)$ \\
Infarction/haemorrhage & $9 / 5(64.3 / 35.7)$ & $9 / 3(75 / 25)$ \\
MMSE & $26.57(2.03)$ & $27.42(1.78)$ \\
BBS & $34.43(3.78)$ & $34.75(2.56)$ \\
Affect side step length $(\mathrm{cm})$ & $32.07(9.48)$ & $35.49(10.45)$ \\
Sound side step length $(\mathrm{cm})$ & $31.21(9.41)$ & $31.54(13.39)$ \\
Gait speed (cm/s) & $35.14(20.59)$ & $38.40(19.86)$ \\
Cadence (step/min) & $61.03(21.48)$ & $69.65(17.92)$ \\
\hline
\end{tabular}

Values are presented as n (\%) or mean (SD).

BWSTT: Body Weight Support Treadmill Training, MMSE: Mini Mental State Examination, BBS: Berg Balance Scale. 
treadmill was decided at this speed [16]. The gait speed was increased in the experimental group [12].

\section{Body weight support treadmill training program}

Gait training using a treadmill was equivalent to the treadmill training program. Subjects walked with body weight

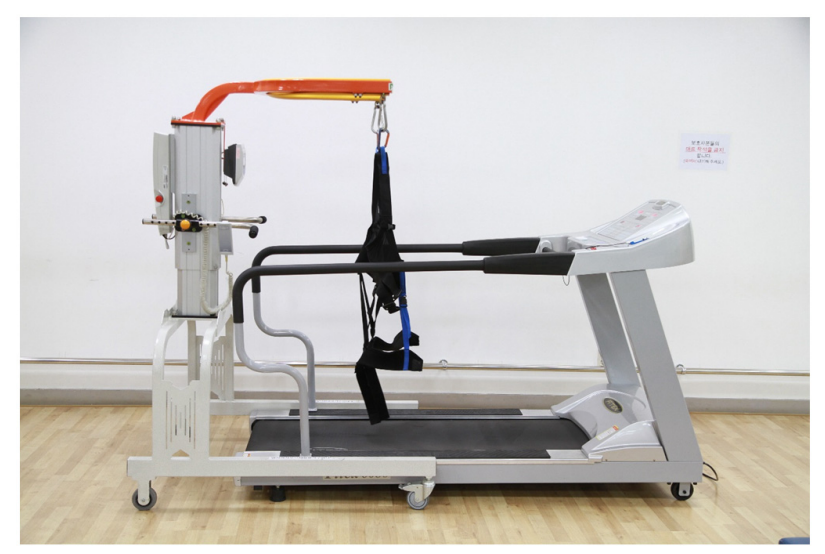

Figure 1. Device for body weight support (LINAK, Silkeborg, Denmark) and treadmill (FITEX T-5050; Fitex, Gwangju, Korea) and treadmill. support (LINAK, Silkeborg, Denmark, 2009; Figure 1). The body weight support device supported $40 \%$ of the patient's weight $[9,17]$. Body weight support was reduced by $5 \%$ and gait speed was increased by $0.2 \mathrm{~km} / \mathrm{h}$ when patients stably walked for 3 minutes [12].

\section{Conventional training program}

Both groups were treated with conventional therapy. Conventional training was composed of range of motion exercise, strengthening exercise, functional movement re-education, and mat exercise.

\section{Outcome measures}

At pre- and post-test, BBS and GAITRite (CIR Systems, Sparta, NJ, USA) tests were used in assessment of balance and gait function of subjects.

BBS is identified as the most commonly used assessment tool in stroke rehabilitation [18-20]. BBS is performed with 14 subcategories. The subcategories are sitting to standing, standing unsupported, sitting unsupported, standing to sitting, transfers, standing with eyes closed, standing with feet together, reaching forward with outstretched arm, retrieving
A

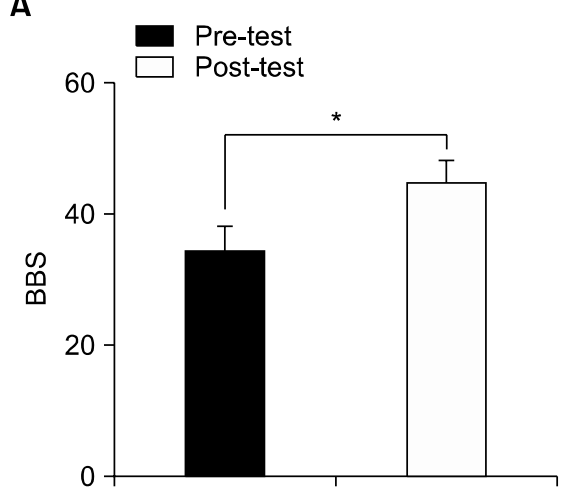

D

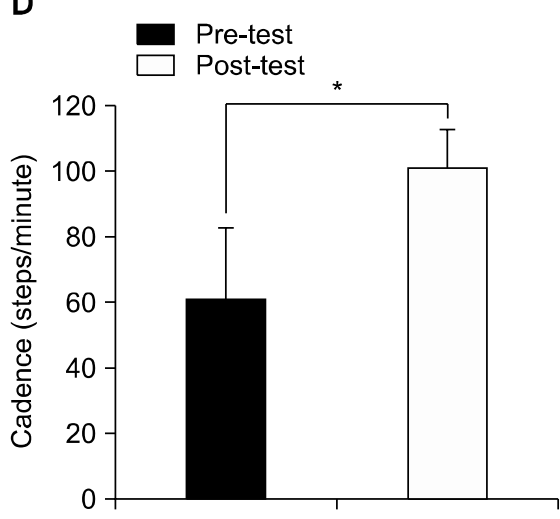

B

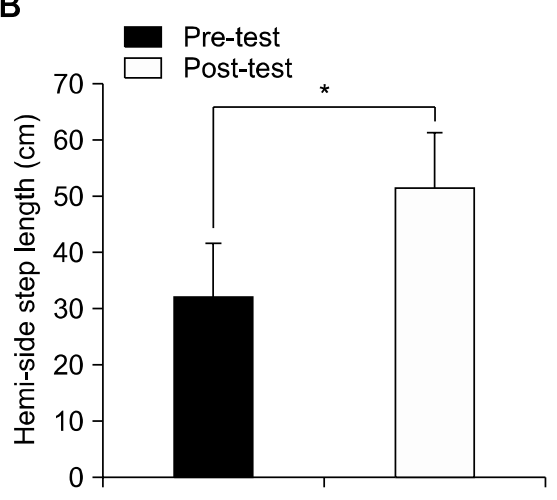

E

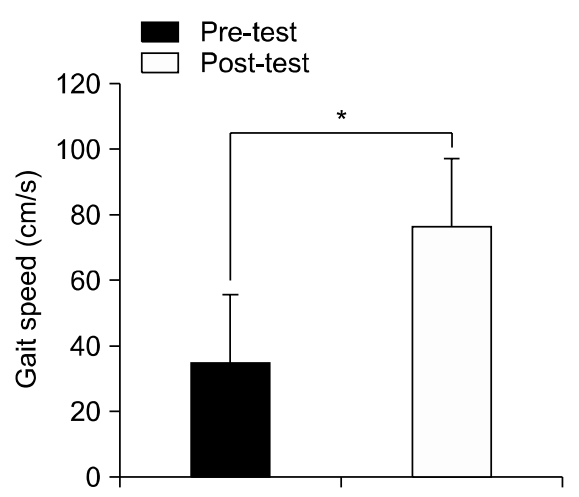

C

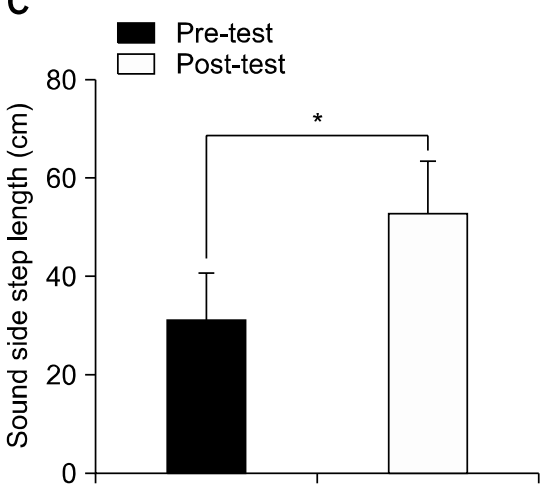

Figure 2. The differences within the Body Weight Support Treadmill Training group after intervention $(n=14)$. Data shown in the figure are the mean (SD). (A) Berg Balance Scale (BBS) score, (B) hemi-side step length, (C) sound side step length, (D) cadence, (E) gait speed. ${ }^{*} p 0.05$. 
object from floor, turning to look behind, turning 360 degrees, placing alternate foot on stool, standing with one foot in front, and standing on one foot. An agreement between the raters was excellent (intraclass correlation coefficient $[\mathrm{ICC}]=0.98)$, and consistency was also excellent within the same rater at two points in time $(\mathrm{ICC}=0.97)$ [20].

GAITRite is a portable gait analysis tool for automated measurement of spatiotemporal gait parameters [21]. As subjects walked along the GAITRite walkway, the sensors captured gait parameters. The gait parameters were transferred to a personal computer for processing. The reliability of walking speed, cadence and step length were excellent (ICCs between 0.82 and 0.92 and coefficients of variations between 1.4 and 3.5\%) [22]. Subjects went through 3 trials and all values were averaged. The gait parameter were step length, cadence and gait speed.

\section{Data analysis}

Statistical analyses were performed using PASW Statistics version 18.0 (IBM Co., Armonk, NY, USA). Data of the subject who completed the study were analysed.
Descriptive statistics were used to compare the general characteristics and pre-test score of the two study groups. A paired t-test was used to assess the significant difference between the pre-test and post-test. An independent t-test was used to assess the significant difference between the experimental group and control group. The level of statistical significance was set at a $p$ level of 0.05 .

\section{Results}

There was a significant difference between the pre-test and post-test for gait variable and balance in both groups.

BBS score, 10.50 (4.6); affect side step length, 19.59 (8.06) $\mathrm{cm}$; sound side step length, $21.63(8.86) \mathrm{cm}$; cadence, 40.21 (13.93) step/min; and gait speed, $41.42(10.69) \mathrm{cm} / \mathrm{s}$ were increased in the BWSTT group ( $p<0.05$; Figure 2 ).

BBS score, 6.16 (2.89); affect side step length, 9.19 (9.39) $\mathrm{cm}$; sound side step length, $9.66(7.71) \mathrm{cm}$; cadence, 16.34 (14.13) step/min; and gait speed, $17.29(12.43) \mathrm{cm} / \mathrm{s}$ were increased in the control group ( $p<0.05$; Figure 3 ).

There was a significant difference in the amount of
A

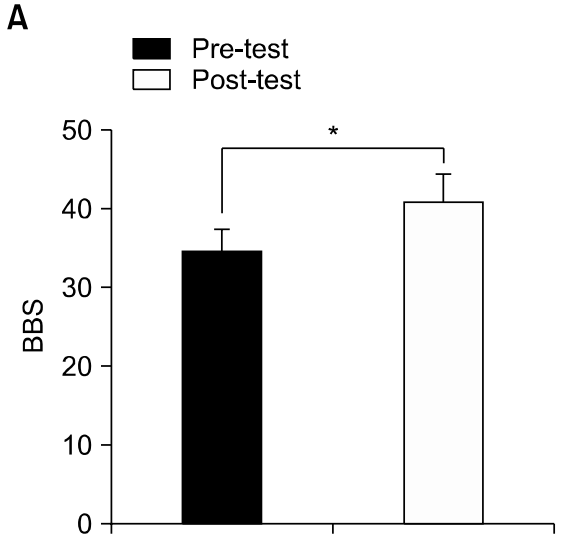

D

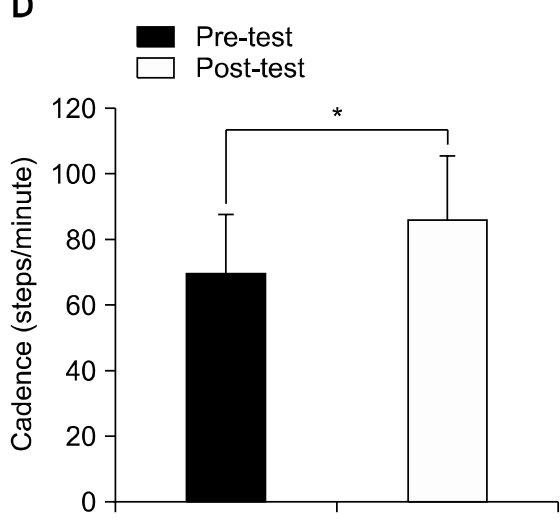

B

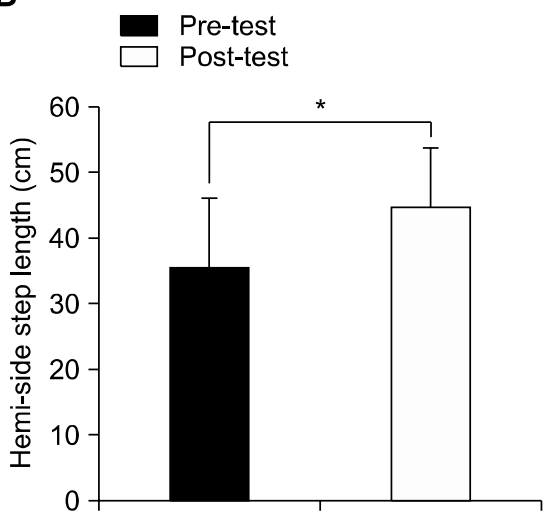

E

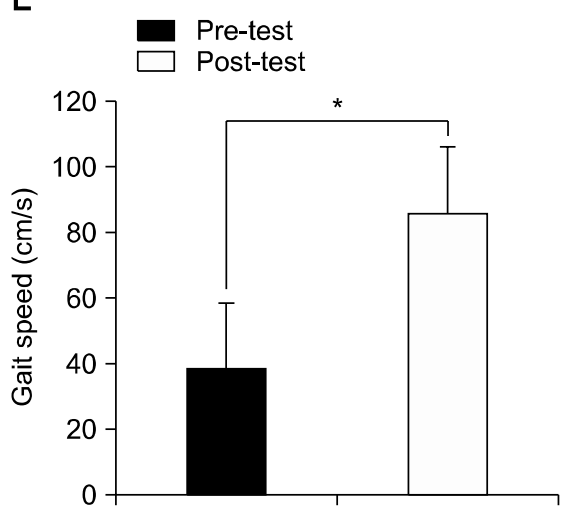

C

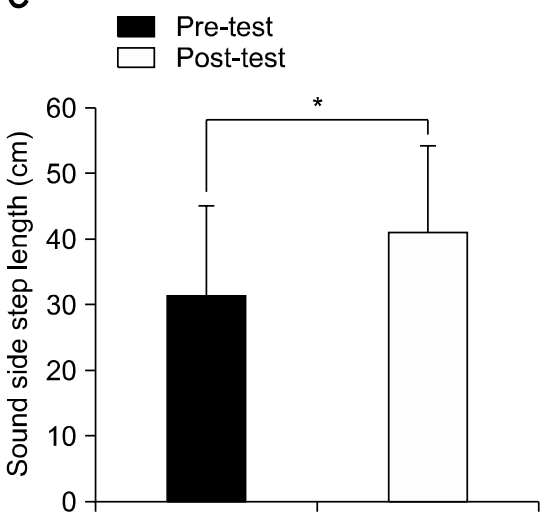

Figure 3. The differences within the control group after intervention $(n=12)$. Data shown in the figure are the mean (SD). (A) Berg Balance Scale (BBS) score, (B) hemi-side step length, $(C)$ sound side step length, (D) cadence, (E) gait speed. ${ }^{*} p<$ 0.05 . 
change in the BWSTT group and control group $(p<0.05$; Figure 4). In the BWSTT group, BBS score, 4.33 (1.54); affect side step length, $10.40(3.42) \mathrm{cm}$; sound side step length, 11.97 (3.29) cm; cadence, 23.88 (5.52) step/min; and gait speed, $24.13(4.53) \mathrm{cm} / \mathrm{s}$ were higher than the control group mean (SD).

\section{Discussion}

This study aimed to determine the effect of intensive gait training with BWSTT on gait and balance in ambulatory stroke patients and to be used as basic materials for application to the clinical effect.

Improved results were visible in both the experimental group and control group after 4 weeks of intervention (Figures 2, 3). However, the amount of change was higher in the BWSTT group than in the control group (Figure 4). These results are in accordance with the results of previous studies [9,17,23-25].

Balance, coordination and muscle power is required for the process of walking [26-28]. The decrease of coordina- tion and muscle weakness is one of the reasons that patients are unable to walk after stroke. Stroke patient have a high risk of falling and short walking distances.

Patients with the body weight support device may increase the walking speed and walking distance than those without the body weight support device $[13,15]$. In the current study, Body Weight Support device played a role in providing stability and created the movements necessary for walking with more ease through reduced loading to the lower extremity. Experimental group can be repeatedly walking training at a faster rate than control group. The repetitive training will help to achieve functional activity again [29-31]. Therefore, it can be speculated that BWSTT had a rapid and repetitive treadmill training effect, leading to improvement of the experimental group.

Balance training was possible by giving the opportunity to maintain the balance required for fast walking.

The effect of BWSTT is better in more severely impaired or older patients [32]. However, this part could not be confirmed in this study because patients who attended this study could walk.
A
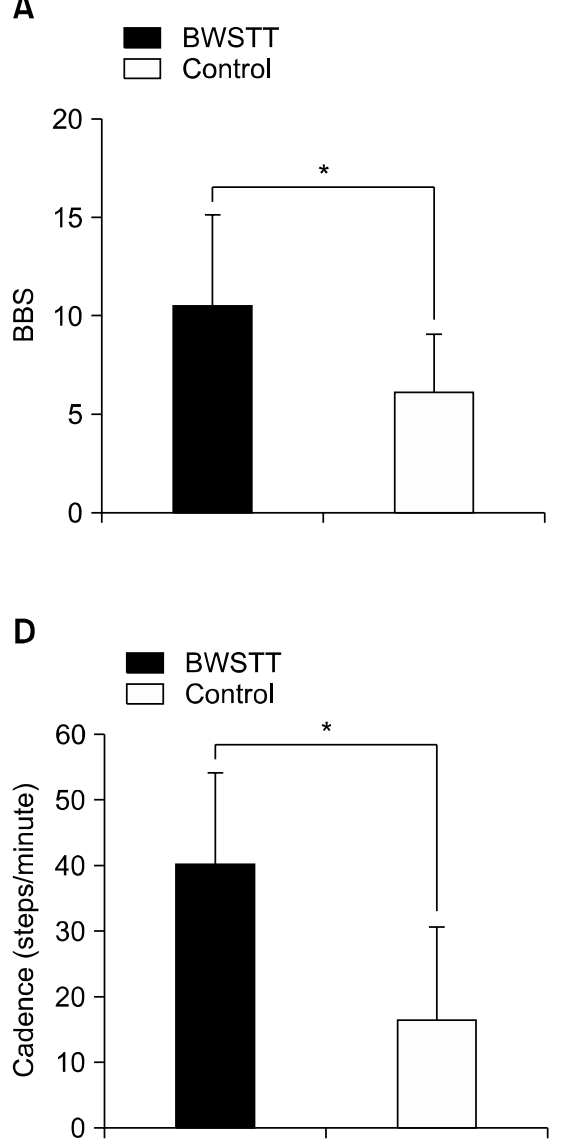

B

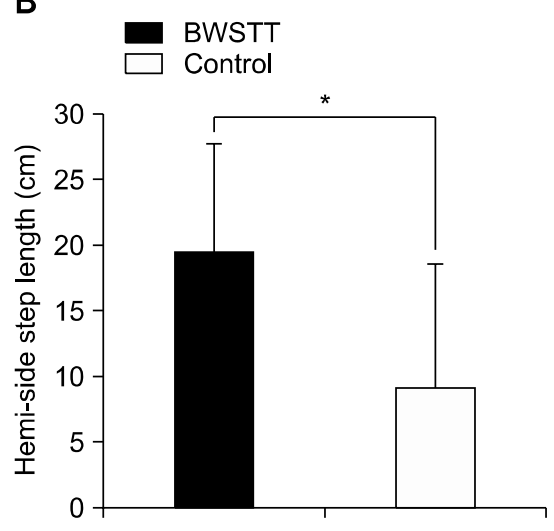

E

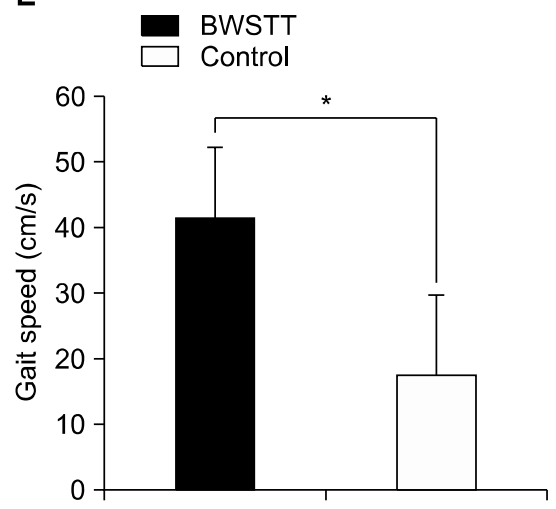

C

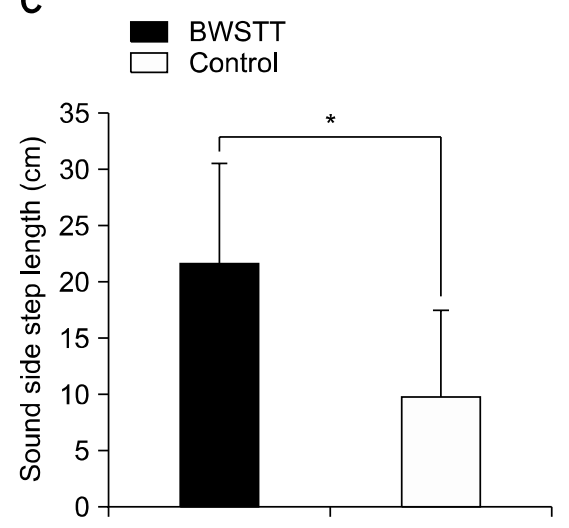

Figure 4. The changes between groups after intervention $(n=24)$. Data shown in the figure are the mean (SD). (A) Berg Balance Scale (BBS) score, (B) hemi-side step length, (C) sound side step length, (D) cadence, (E) gait speed. BWSTT: Body Weight Support Treadmill Training. ${ }^{*} p<$ 0.05 . 
The effect of BWSTT transfers over to ground locomotion [24,32]. It is believed that the results of this study may have implications to real life.

The limitation of this study was that any effect in chronic stroke patient could not be for certain because subjects were subacute patients. The lasting effect of BWSTT after training was unclear since there was no follow-up. The treadmill speed had been increased to subjective judgment of the patient. Further research is required with the use of heart rate monitoring for deciding treadmill speed and to generalize these findings.

\section{References}

1. Langhorne P, Bernhardt J, Kwakkel G. Stroke rehabilitation. Lancet 2011;377:1693-702.

2. Dickstein R, Dunsky A, Marcovitz E. Motor imagery for gait rehabilitation in post-stroke hemiparesis. Phys Ther 2004;84: 1167-77.

3. Yan T, Hui-Chan CW, Li LS. Functional electrical stimulation improves motor recovery of the lower extremity and walking ability of subjects with first acute stroke: a randomized placebo-controlled trial. Stroke 2005;36:80-5.

4. Suh JH, Han SJ, Jeon SY, Kim HJ, Lee JE, Yoon TS, et al. Effect of rhythmic auditory stimulation on gait and balance in hemiplegic stroke patients. NeuroRehabilitation 2013. [Epub ahead of print]

5. Sale P, Franceschini M, Waldner A, Hesse S. Use of the robot assisted gait therapy in rehabilitation of patients with stroke and spinal cord injury. Eur J Phys Rehabil Med 2012;48:111-21.

6. Silver KH, Macko RF, Forrester LW, Goldberg AP, Smith GV. Effects of aerobic treadmill training on gait velocity, cadence, and gait symmetry in chronic hemiparetic stroke: a preliminary report. Neurorehabil Neural Repair 2000;14:65-71.

7. Lamontagne A, Fung J. Faster is better: implications for speedintensive gait training after stroke. Stroke 2004;35:2543-8.

8. Peurala SH, Airaksinen O, Huuskonen P, Jäkälä P, Juhakoski M, Sandell K, et al. Effects of intensive therapy using gait trainer or floor walking exercises early after stroke. J Rehabil Med 2009; 41:166-73.

9. Visintin M, Barbeau H, Korner-Bitensky N, Mayo NE. A new approach to retrain gait in stroke patients through body weight support and treadmill stimulation. Stroke 1998;29:1122-8.

10. Malouin F, Potvin M, Prévost J, Richards CL, Wood-Dauphinee $\mathrm{S}$. Use of an intensive task-oriented gait training program in a series of patients with acute cerebrovascular accidents. Phys Ther 1992;72:781-9.

11. Chung EJ, Lee BH. The effects of treadmill training on dynamic balance and gait function in stroke patients: a pilot randomized controlled trial. Phys Ther Rehabil Sci 2013;2:39-43.

12. McCain KJ, Pollo FE, Baum BS, Coleman SC, Baker S, Smith PS. Locomotor treadmill training with partial body-weight support before overground gait in adults with acute stroke: a pilot study. Arch Phys Med Rehabil 2008;89:684-91.

13. Sousa CO, Barela JA, Prado-Medeiros CL, Salvini TF, Barela
AM. Gait training with partial body weight support during overground walking for individuals with chronic stroke: a pilot study. J Neuroeng Rehabil 2011;8:48.

14. Ada L, Dean CM, Morris ME. Supported treadmill training to establish walking in non-ambulatory patients early after stroke. BMC Neurol 2007;7:29.

15. Ada L, Dean CM, Morris ME, Simpson JM, Katrak P. Randomized trial of treadmill walking with body weight support to establish walking in subacute stroke: the MOBILISE trial. Stroke 2010;41:1237-42.

16. Lindquist AR, Prado CL, Barros RM, Mattioli R, da Costa PH, Salvini TF. Gait training combining partial body-weight support, a treadmill, and functional electrical stimulation: effects on poststroke gait. Phys Ther 2007;87:1144-54.

17. Sullivan KJ, Knowlton BJ, Dobkin BH. Step training with body weight support: effect of treadmill speed and practice paradigms on poststroke locomotor recovery. Arch Phys Med Rehabil 2002;83:683-91.

18. Blum L, Korner-Bitensky N. Usefulness of the Berg Balance Scale in stroke rehabilitation: a systematic review. Phys Ther 2008;88:559-66.

19. de Oliveira CB, de Medeiros IR, Frota NA, Greters ME, Conforto AB. Balance control in hemiparetic stroke patients: main tools for evaluation. J Rehabil Res Dev 2008;45:1215-26.

20. Berg K, Wood-Dauphinee S, Williams JI. The Balance Scale: reliability assessment with elderly residents and patients with an acute stroke. Scand J Rehabil Med 1995;27:27-36.

21. Bilney B, Morris M, Webster K. Concurrent related validity of the GAITRite walkway system for quantification of the spatial and temporal parameters of gait. Gait Posture 2003;17:68-74.

22. Menz HB, Latt MD, Tiedemann A, Mun San Kwan M, Lord SR. Reliability of the GAITRite walkway system for the quantification of temporo-spatial parameters of gait in young and older people. Gait Posture 2004;20:20-5.

23. Laufer Y, Dickstein R, Chefez Y, Marcovitz E. The effect of treadmill training on the ambulation of stroke survivors in the early stages of rehabilitation: a randomized study. J Rehabil Res Dev 2001;38:69-78.

24. Peurala SH, Tarkka IM, Pitkänen K, Sivenius J. The effectiveness of body weight-supported gait training and floor walking in patients with chronic stroke. Arch Phys Med Rehabil 2005;86: 1557-64.

25. Combs SA, Dugan EL, Ozimek EN, Curtis AB. Bilateral coordination and gait symmetry after body-weight supported treadmill training for persons with chronic stroke. Clin Biomech (Bristol, Avon) 2013;28:448-53.

26. Michael KM, Allen JK, Macko RF. Reduced ambulatory activity after stroke: the role of balance, gait, and cardiovascular fitness. Arch Phys Med Rehabil 2005;86:1552-6.

27. Yavuzer G, Eser F, Karakus D, Karaoglan B, Stam HJ. The effects of balance training on gait late after stroke: a randomized controlled trial. Clin Rehabil 2006;20:960-9.

28. Stephenson JL, Lamontagne A, De Serres SJ. The coordination of upper and lower limb movements during gait in healthy and stroke individuals. Gait Posture 2009;29:11-6.

29. Kawahira K, Shimodozono M, Ogata A, Tanaka N. Addition of intensive repetition of facilitation exercise to multidisciplinary rehabilitation promotes motor functional recovery of the hemi- 
plegic lower limb. J Rehabil Med 2004;36:159-64.

30. Dombovy ML. Understanding stroke recovery and rehabilitation: current and emerging approaches. Curr Neurol Neurosci Rep 2004;4:31-5.

31. French B, Thomas LH, Leathley MJ, Sutton CJ, McAdam J, Forster A, et al. Repetitive task training for improving functional ability after stroke. Cochrane Database Syst Rev 2007;(4): CD006073.

32. Barbeau H, Visintin M. Optimal outcomes obtained with body-weight support combined with treadmill training in stroke subjects. Arch Phys Med Rehabil 2003;84:1458-65. 